\title{
BMJ Open Determinants of immunisation coverage of children aged 12-59 months in Indonesia: a cross-sectional study
}

\author{
Putri Herliana, Abdel Douiri
}

To cite: Herliana P, Douiri A. Determinants of immunisation coverage of children aged 12-59 months in Indonesia: a cross-sectional study. BMJ Open 2017;7:e015790. doi:10.1136/ bmjopen-2016-015790

- Prepublication history for this paper is available online. To view these files, please visit the journal online (http://dx.doi. org/10.1136/bmjopen-2016015790).

Received 30 December 2016 Revised 23 August 2017 Accepted 8 September 2017

CrossMark

Department of Primary Care and Public Health Sciences, King's College London, London, UK

Correspondence to

Putri Herliana;

putri.herliana@kcl.ac.uk

\section{ABSTRACT}

Objectives Despite the adoption of WHO's Expanded Programme on Immunisation in Indonesia since 1977, a large proportion of children are still completely unimmunised or only partly immunised. This study aimed to assess factors associated with low immunisation coverage of children in Indonesia.

Setting Children aged 12-59 months in Indonesia. Participant The socioeconomic characteristics and immunisation status of the children were obtained from the most recent Demographic and Health Survey, the 2012 Indonesia Demographic and Health Survey. Participants were randomly selected through a two-stage stratified sampling design. Data from 14401 children aged 12-59 months nested within 1832 census blocks were included in the analysis. Multilevel logistic regression models were constructed to account for hierarchical structure of the data.

Results The mean age of the children was 30 months and they were equally divided by sex. According to the analysis, $32 \%$ of the children were fully immunised in 2012. Coverage was significantly lower among children who lived in Maluku and Papua region (adjusted OR: 1.94; $95 \% \mathrm{Cl} 1.42$ to 2.64$)$, were $36-47$ months old (1.39; 1.20 to 1.60$)$, had higher birth order (1.68; 1.28 to 2.19$)$, had greater family size $(1.47 ; 1.11$ to 1.93$)$, whose mother had no education $(2.13 ; 1.22$ to 3.72$)$ and from the poorest households (1.58; 1.26 to 1.99$)$. The likelihood of being unimmunised was also higher among children without health insurance $(1.16 ; 1.04$ to 1.30 ) and those who received no antenatal $(3.28 ; 2.09$ to 5.15$)$ and postnatal care $(1.50 ; 1.34$ to 1.69$)$.

Conclusions Socioeconomic factors were strongly associated with the likelihood of being unimmunised in Indonesia. Unimmunised children were geographically clustered and lived among the most deprived population. To achieve WHO target of protective coverage, public health interventions must be designed to meet the needs of these high-risk groups.

\section{BACKGROUND}

In 1974, the WHO initiated the Expanded Programme on Immunisation (EPI) with the goal of providing universal immunisation for all children. ${ }^{1}$ The first diseases targeted were diphtheria, tetanus, pertussis, polio, measles and tuberculosis. ${ }^{1}$ New and increasingly sophisticated vaccines have become

\section{Strengths and limitations of this study}

- Our study investigated, for the first time, the factors associated with routine immunisation coverage of children in Indonesia using data from the most recent demographic and health survey.

- The large sample size allowed us to analyse many potential predictors simultaneously and produce reliable estimates.

- We used multilevel modelling to account for the hierarchical structure of the data.

- However, we could only build a two-level model (ie, children nested within census blocks) instead of the ideal three-level model (ie, children within households nested within census blocks) because there was no household identifier in the dataset, as it may compromise the participants' anonymity.

- The selection of variables included in this study also relied on the information available from the dataset.

available, and more children than ever before are being vaccinated today. ${ }^{23}$ Global coverage increased from $74 \%$ in 2000 to $86 \%$ in 2014 . $^{4}$ As a result, the annual number of child deaths fell from 9.6 million in 2000 to 5.9 million in 2015. ${ }^{14}$ Immunisation drives this reduction in child mortality and the collective recognition has led to the development of the Global Vaccine Action Plan (GVAP), a framework to help countries achieve universal child immunisation by $2020 .{ }^{3}$ The target, as stated in the United Nations Sustainable Development Goals, is to end preventable child deaths by $2030 .^{5}$

Despite this progress, vaccine-preventable diseases are still responsible for 1.5 million child deaths each year. ${ }^{6}$ Almost 18.7 million children were not given routine immunisation in 2014, and $75 \%$ of them live in only 10 countries in Africa and Asia. ${ }^{4}$ Although some regions have successfully maintained a high level of immunisation coverage, there are pockets of unimmunised children which induce the continuous spread of diseases and outbreaks. ${ }^{2}$ This highlights the fact that global coverage may hide variability between 
countries. It also suggests that the achievements are still fragile. Should this trend continue, the goals of providing universal immunisation for all children by 2020 and ending vaccine-preventable deaths by 2030 could not be achieved, and the cost of such failure would be close to 26 million deaths. ${ }^{3}$

One of the 10 countries that are home to the highest number of unimmunised children is Indonesia. ${ }^{4}$ Indonesia is a lower middle-income country located in Southeast Asia. ${ }^{7}$ It has an estimated population of over 255 million in $2015,10 \%$ of whom are children under the age of five. ${ }^{8}$ Child mortality rate in Indonesia currently stands at 27 deaths per 1000 births and ranks 101st out of 175 countries. ${ }^{9}$ Approximately $36 \%$ of child deaths were caused by infectious diseases. ${ }^{10}$ For most of these diseases, vaccines are available to prevent child deaths.

The Indonesian Ministry of Health $(\mathrm{MOH})$, which organises public health matters within the Indonesian government, has adopted and implemented the EPI guidelines since 1977 through a routine immunisation programme that is compulsory for all children. ${ }^{11}$ Even so, a large number of young children in Indonesia are still either completely unimmunised or only partly immunised. In 2013, the MOH has reported that only $59.2 \%$ of children were fully immunised. ${ }^{11}$ There were also striking gaps within the country as coverage was as low as $29.2 \%$ at a certain area in Indonesia. ${ }^{11}$ These figures were well below the $90 \%$ advised threshold that is required to maintain herd immunity and prevent the spread of diseases. ${ }^{3}$ As the fourth most populous country in the world with a great proportion of young children, the risk of large and uncontrollable outbreaks in Indonesia is more likely than ever.

To significantly increase coverage in Indonesia, a strategy proposed by GVAP is to identify and engage the unimmunised children. ${ }^{3}$ These children are often the ones carrying a heavier burden of diseases. ${ }^{3}$ There is particular concern that diseases may thrive when unimmunised children are residentially segregated from immunised children. ${ }^{2}$ It is therefore critical to know who they are, where they live and what factors might have contributed to their unimmunised status to ascertain where greater efforts are needed.

While administrative and geographic barriers may contribute to low coverage in a country with such a large population, ${ }^{12}$ GVAP explicitly highlights the importance of socioeconomic factors in determining coverage. ${ }^{3}$ Theory suggests that factors such as income level, employment status and education are major determinants of healthcare ${ }^{\text {use, } 13}$ and a growing body of empirical evidence advances such association. The socioeconomic characteristics attached to routine immunisation coverage, and the extent these factors may play a role, vary by country. ${ }^{12}$ 14-24 However, no such research has been done in Indonesia.

In this study, we used data from the 2012 Indonesia Demographic and Health Survey (IDHS) which collected information on both the immunisation status and the socioeconomic characteristics of Indonesian children under 5 years of age. Our aim was to identify the socioeconomic factors associated with routine immunisation coverage of children in Indonesia. The results should help in identifying susceptible subgroups of the population that require additional resources and focused attention.

\section{METHODS}

\section{Data source}

This study is a secondary data analysis of the most recent DHS in Indonesia. The IDHS is conducted routinely by the national statistics authority Statistics Indonesia, in collaboration with the National Population and Family Planning Board, the Indonesian MOH and ICF International. ${ }^{25}$ Studies on its quality suggest that DHS is nationally representative, with little evidence of systematic bias. ${ }^{26}$

Data were collected from 7 May to 31 July 2012. Participants were selected through a two-stage stratified sampling design. The primary sampling unit was the census block (CB) and the complete list of households in each $\mathrm{CB}$ became the basis for second-stage sampling. A total of 46024 households were chosen as the sample. From 44302 occupied households, 45607 women aged 15-49 were successfully interviewed, yielding a response rate of $96 \%$.

The Women's Questionnaire included questions about the woman's background characteristics and her children aged under 5 , for whom immunisation and health data were collected. The dataset had one record for every child of each interviewed woman, born in the 5 years preceding the survey. Data were obtained for 18021 children.

\section{Outcome variable}

The outcome variable in the analysis was the child's immunisation status. Information on immunisation status was collected from two sources, the health card or health book shown to the interviewer or if unavailable from the mother's report. The health card or health book was available $85.77 \%$ of the time.

The outcome variable was categorised as 'fully immunised' if they had received the full schedule of routine immunisation and otherwise 'unimmunised', regardless of the source of the information. Routine immunisation referred to three doses of DTP vaccines, four doses of polio vaccine, one dose of measles vaccine, one dose of Bacillus Calmette-Guérin (BCG) vaccine and four doses of hepatitis $B$ vaccine, scheduled to be received by the age of 12 months. ${ }^{11}$ The proportion of children who had been fully immunised defined immunisation coverage. ${ }^{27}$

In a small number of cases, where health cards were unavailable and mothers indicated that they did not know about the immunisation status $(1.51 \%)$, the child was considered as not fully immunised. The fact that mothers responded 'don't know' is likely to reflect that the child was not fully immunised ${ }^{12} 28$ and fits better in the 'unimmunised' category. 


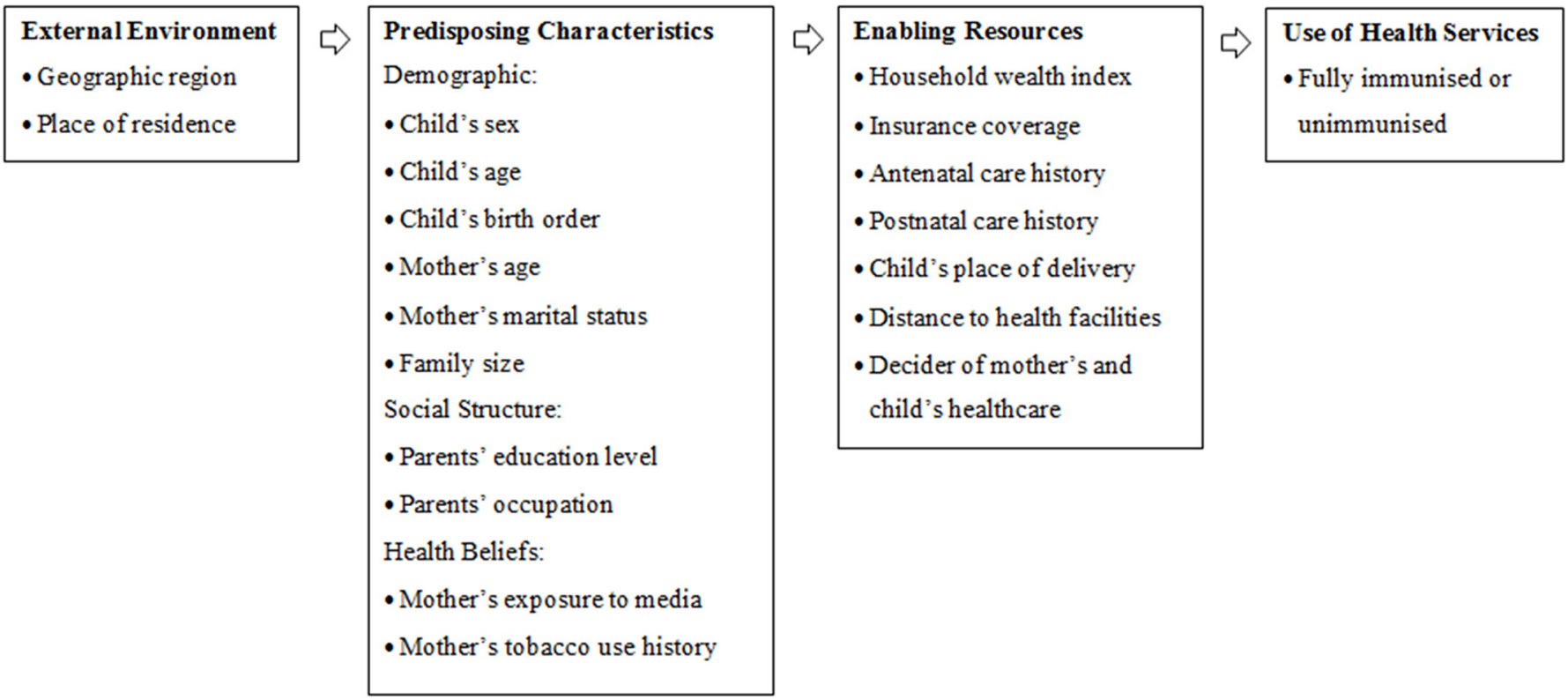

Figure 1 Theoretical framework of factors potentially associated with immunisation coverage of children in Indonesia, informed by Andersen's Behavioural Health Model.

\section{Independent variables}

Selection of independent variables was based on the literature review and variables available in the dataset. Twenty-two independent variables were identified as potential factors and Andersen's Behavioural Health Model ${ }^{13}$ was used as a framework to group the factors into three main groups: external environment, predisposing and enabling factors (figure 1). The model has been commonly used to examine factors associated with health service use, including immunisation uptake. ${ }^{21} 29$

Predisposing characteristics consist of demographic factors, social structure such as educational attainment and occupation and health beliefs which involve health-related knowledge and behaviours. ${ }^{13}$ Enabling resources are related to individuals' personal and community support which enable them to use health services, reflected by income level, insurance coverage and other factors that could affect one's access to health services. ${ }^{13}$ Lastly, external environment incorporates wider social and environmental determinants of health. ${ }^{13}$

Categorisation of continuous variables and description of categorical variables were undertaken according to the literature. The child's age (12-59 months) was categorised into groups at 1-year intervals. Similarly, the mother's age (15-49 years) was categorised into groups at 5-year intervals. The child's birth order and family size were also categorised into groups based on previously published literatures.

Following IDHS protocol, ${ }^{25}$ household wealth index was constructed based on household amenities and assets (radio, television, refrigerator, bicycle, motorcycle or car) and dwelling characteristics (electricity, flooring, roofing, water source, toilet facilities and sleeping arrangements). It was categorised into quintiles from poorest to richest. In the absence of direct information on household income or expenditures, wealth index is considered a robust measure of household income level. ${ }^{30}$ Insurance coverage represented any health insurance provided through social security or local government, by employer, privately purchased or other insurance. Antenatal care represented any pregnancy-related care provided by skilled health personnel or traditional birth attendants during the pregnancy, irrespective of the type of provider and the number of visits. Similarly, postnatal care represented any examination by skilled health personnel or traditional birth attendants within 2 months of the child's birth, irrespective of the type of provider and the number of visits.

The 33 provinces in Indonesia were categorised into six island-based regions. ${ }^{25}$ The child's place of delivery was classified into three categories: home, public health institution and private health institution. Public health institution included public hospitals, public clinics, health centres, village health posts and delivery posts. Private health institution included private hospitals, private clinics, maternity hospitals, maternity home and also private practices of obstetrician, general practitioner, nurse, midwife and village midwife.

\section{Statistical analysis}

The original dataset comprised of 18021 children aged 0-59 months distributed among 1840 CBs. For the purpose of the analysis, we excluded 3620 children who were under 1 year old because they were not old enough to have received the full schedule of routine immunisation in Indonesia. The final sample, therefore, contained 14401 children from 1832 CBs. From this, we had 656 children $(4.6 \%)$ with missing immunisation status because they were no longer alive at the time of the survey, leaving complete observations of 13745 children 
$(95.4 \%)$. Given the small number of missing values, we used complete case analysis and no sensitivity analysis was required.

Data analysis was conducted using STATA V.14 software. Frequency and percentage were used to report baseline characteristics of the children. Cross-tabulation was undertaken to demonstrate the proportion of different categories with respect to immunisation status. The immunisation status as outcome variable was coded into 0 for 'fully immunised' and 1 for otherwise 'unimmunised'.

Univariate analysis was used to separately evaluate the effect of each independent variable on the outcome variable. Test of trends across ordered groups were evaluated. Variables with a univariate $\mathrm{p}$ Value of less than 0.2 were then selected as candidates for the multivariate analysis.

Multilevel logistic regression was used to estimate immunisation status in multivariate context while accounting for clustering. Model fitting using residuals were checked. A two-level model was used for the multivariate analysis (ie, children nested within CBs). This was run using the meqrlogit command in STATA V.14, a method based on maximum likelihood and robust to missing values. Associations between independent variables and the likelihood of children being unimmunised were assessed simultaneously. The results were expressed as adjusted OR with $95 \%$ CI.

\section{RESULTS}

\section{Descriptive statistics}

A total of 14401 children from $1832 \mathrm{CBs}$ were included in the analysis. Our result showed that only $31.5 \%$ (95\% CI $30.7 \%$ to $32.3 \%$ ) of the children aged $12-59$ months had been fully immunised at the time of the survey. The baseline characteristics of sample were presented in table 1 .

The mean age of the children was 30 months and they were equally divided by sex. More than half of them were second to fourth born. The mothers were 25 to 29 years old on average and almost all were married at the time of the survey. Most of the families had five to nine household members.

Majority of the mothers were secondary school graduates. Although educational attainment was approximately equal for both parents, nearly half of the mothers did not work. A large proportion of the mothers were exposed to media at least once a week and almost all reported that they did not smoke around the time of the survey.

In terms of enabling resources, half of the children lived in the poorer and poorest households. Additionally, almost two-thirds of the children were not covered by health insurance. While only a small proportion were born without antenatal care, much more children were born without postnatal care. Nearly half of the children were delivered at home although most mothers reported that distance to health facilities were not a big problem. Lastly, the majority of mothers reported that they were involved in the decision-making process of their own healthcare as well as their children's.
Table 1 Baseline characteristics of sample $(n=14401)$

\begin{tabular}{lcc}
\hline Characteristics & Frequency* & Percentage (\%) \\
\hline Immunisation status & & \\
$\quad$ Fully immunised & 4331 & 31.5 \\
$\quad$ Unimmunised & 9414 & 68.5 \\
External environment & & \\
Geographic region & & \\
$\quad$ Sumatera & 4061 & 29.5 \\
Java & 3079 & 22.4 \\
Bali and Nusa Tenggara & 1220 & 9.0 \\
Kalimantan & 1447 & 10.5 \\
Sulawesi & 2381 & 17.3 \\
$\quad$ Maluku and Papua & 1557 & 11.3 \\
Place of residence & & \\
$\quad$ Urban & 6307 & 45.9 \\
Rural & 7438 & 54.1
\end{tabular}

Predisposing characteristics
Child's sex

$\begin{array}{lll}\text { Male } & 7092 & 51.6 \\ \text { Female } & 6653 & 48.4\end{array}$

Child's age (months)

$\begin{array}{lll}12-23 & 3501 & 25.5 \\ 24-35 & 3413 & 24.8 \\ 36-47 & 3378 & 24.6 \\ 48-59 & 3453 & 25.1\end{array}$

\section{Child's birth order}

1st $\quad 5929 \quad 35.9$

2nd-4th $\quad 7533 \quad 54.8$

$\begin{array}{lll}\geq 5 \text { th } & 1283 & 9.3\end{array}$

\begin{tabular}{lrr} 
Mother's age (years) & 262 & 1.9 \\
\hline $15-19$ & 2381 & 17.3 \\
$20-24$ & 3928 & 28.6 \\
$25-29$ & 3454 & 25.2 \\
$30-34$ & 2410 & 17.5 \\
$35-39$ & 1104 & 8.0 \\
$40-44$ & 206 & 1.5 \\
$45-49$ & & \\
Mother's marital status & 13168 & 95.8 \\
Married & 176 & 1.3 \\
Living with partner & 118 & 0.8 \\
Widowed & 231 & 1.7 \\
Divorced & 43 & 0.3 \\
No longer living together & 9 & 0.1 \\
Never in union & 5314 & 38.6 \\
Family size (number of household members) \\
54 \\
5-9 & 7637 & 55.6 \\
\hline
\end{tabular}

Continued 


\begin{tabular}{|c|c|c|}
\hline Characteristics & Frequency* & Percentage (\%) \\
\hline$\geq 10$ & 794 & 5.8 \\
\hline \multicolumn{3}{|l|}{ Mother's educational level } \\
\hline Higher & 1819 & 13.2 \\
\hline Secondary & 7221 & 52.6 \\
\hline Primary & 4291 & 31.2 \\
\hline No education & 414 & 3.0 \\
\hline \multicolumn{3}{|l|}{ Father's educational level } \\
\hline Higher & 1740 & 12.7 \\
\hline Secondary & 7438 & 54.2 \\
\hline Primary & 4204 & 30.6 \\
\hline No education & 311 & 2.3 \\
\hline Don't know & 24 & 0.2 \\
\hline \multicolumn{3}{|l|}{ Mother's occupation } \\
\hline Professional & 1018 & 7.4 \\
\hline Agricultural & 1855 & 13.5 \\
\hline Industrial & 1571 & 11.4 \\
\hline Clerical, services and sales & 3236 & 23.6 \\
\hline Did not work & 6052 & 44.1 \\
\hline Do not know & 2 & 0.0 \\
\hline \multicolumn{3}{|l|}{ Father's occupation } \\
\hline Professional & 1336 & 9.8 \\
\hline Agricultural & 3550 & 25.9 \\
\hline Industrial & 4884 & 35.6 \\
\hline Clerical, services and sales & 3709 & 27.0 \\
\hline Did not work & 225 & 1.6 \\
\hline Do not know & 12 & 0.1 \\
\hline
\end{tabular}

Mother's exposure to media (newspaper, magazine, radio or television)

$\begin{array}{lrr}\text { At least once a week } & 11528 & 83.9 \\ \text { Less than once a week } & 1527 & 11.1 \\ \text { Not at all } & 686 & 5.0 \\ \text { Mother's tobacco use history } & & \\ \text { Smokes nothing } & 13317 & 96.9 \\ \text { Uses tobacco } & 424 & 3.1\end{array}$

$\begin{array}{lll}\begin{array}{l}\text { Enabling resources } \\ \text { Household wealth index }\end{array} & \\ \text { Richest } & 2108 & 15.3 \\ \text { Richer } & 2276 & 16.6 \\ \text { Middle } & 2504 & 18.2 \\ \text { Poorer } & 2722 & 19.8 \\ \text { Poorest } & 4135 & 30.1 \\ \text { Covered by health insurance } & \\ \text { Yes } & 5580 & 40.6 \\ \text { No } & 8156 & 59.4 \\ \text { Antenatal care } & \end{array}$

Continued

\begin{tabular}{|c|c|c|}
\hline Characteristics & Frequency* & Percentage (\%) \\
\hline Received some care & 10861 & 96.2 \\
\hline Received no care & 640 & 3.8 \\
\hline \multicolumn{3}{|l|}{ Postnatal care } \\
\hline Received some care & 7395 & 65.7 \\
\hline Received no care & 3813 & 33.8 \\
\hline Don't know & 53 & 0.5 \\
\hline \multicolumn{3}{|l|}{ Child's place of delivery } \\
\hline Home & 6325 & 46.2 \\
\hline Public health institution & 2527 & 18.4 \\
\hline Private health institution & 4823 & 35.2 \\
\hline Other & 28 & 0.2 \\
\hline \multicolumn{3}{|l|}{ Distance to health facilities } \\
\hline Not a big problem & 11915 & 86.9 \\
\hline Big problem & 1792 & 13.1 \\
\hline \multicolumn{3}{|c|}{ Maternal healthcare decision-making } \\
\hline By herself & 4758 & 35.7 \\
\hline Jointly with husband & 6567 & 49.3 \\
\hline Husband alone & 1972 & 14.7 \\
\hline By others & 34 & 0.3 \\
\hline \multicolumn{3}{|c|}{ Child healthcare decision-making } \\
\hline By herself & 4497 & 36.3 \\
\hline Jointly with husband & 1407 & 50.5 \\
\hline Husband alone & 6255 & 11.4 \\
\hline By others & 225 & 1.8 \\
\hline
\end{tabular}

*Total number varies between categories because of missing values.

\section{Univariate analysis}

The association between each independent variable and the likelihood of being unimmunised was investigated one by one. The result were shown in table 2 .

Geographic region came out as a significant predictor of immunisation coverage in our univariate analysis. The majority, one-third, of children who were fully immunised lived in Java, while the lowest coverage was reported in Maluku and Papua. The odds of being unimmunised were almost threefold among children who lived in Maluku and Papua (OR 2.80; 95\% CI 2.42 to 3.24). On the contrary, we found that children from Bali and Nusa Tenggara had the least likelihood of being unimmunised (OR $0.86 ; 95 \%$ CI 0.75 to 0.99 ). Our univariate analysis also showed that children from rural areas were significantly more likely to be unimmunised compared with their urban counterparts (OR 1.39; 95\% CI 1.30 to 1.50 ).

Although coverage was approximately equal for both sexes, the child's age and birth order were significantly associated with coverage. Older children were more likely to be unimmunised compared with the youngest ones. The odds of being unimmunised among the older 
Table 2 Univariate analysis results for factors associated with low immunisation coverage of children aged 12-59 months in Indonesia

\begin{tabular}{|c|c|c|c|c|c|c|}
\hline \multirow{2}{*}{ Characteristics } & \multicolumn{4}{|c|}{ Status (\%) } & \multirow{2}{*}{$\begin{array}{l}\text { Unadjusted OR } \\
(95 \% \mathrm{Cl})\end{array}$} & \multirow[b]{2}{*}{ p Value } \\
\hline & \multicolumn{2}{|c|}{ Fully immunised } & \multicolumn{2}{|c|}{ Unimmunised } & & \\
\hline \multirow{2}{*}{\multicolumn{7}{|c|}{$\begin{array}{l}\text { External environment } \\
\text { Geographic region }\end{array}$}} \\
\hline & & & & & & \\
\hline Sumatera & 1135 & $(26.2)$ & 2926 & $(31.8)$ & 1.68 (1.52 to 1.86$)$ & 0.000 \\
\hline Java & 1215 & $(28.1)$ & 1864 & $(19.8)$ & 1 & \\
\hline Bali and Nusa Tenggara & 525 & $(12.1)$ & 695 & $(7.4)$ & $0.86(0.75$ to 0.99$)$ & 0.032 \\
\hline Kalimantan & 490 & $(11.3)$ & 957 & $(10.2)$ & $1.27(1.12$ to 1.45$)$ & 0.000 \\
\hline Sulawesi & 672 & $(15.5)$ & 1709 & $(18.2)$ & 1.66 (1.48 to 1.86$)$ & 0.000 \\
\hline Maluku and Papua & 294 & (6.8) & 1263 & $(13.4)$ & $2.80(2.42$ to 3.24$)$ & 0.000 \\
\hline \multicolumn{7}{|l|}{ Place of residence } \\
\hline Urban & 2232 & $(51.5)$ & 4075 & $(43.3)$ & 1 & \\
\hline Rural & 2099 & $(48.5)$ & 5339 & $(56.7)$ & 1.39 (1.30 to 1.50$)$ & 0.000 \\
\hline \multicolumn{7}{|c|}{ Predisposing characteristics } \\
\hline \multicolumn{7}{|c|}{ Child's sex } \\
\hline Male & 2255 & $(52.1)$ & 4837 & $(51.4)$ & 1 & \\
\hline Female & 2076 & $(47.9)$ & 4577 & $(48.6)$ & 1.03 (0.96 to 1.10$)$ & 0.455 \\
\hline \multicolumn{7}{|l|}{ Child's age (months) } \\
\hline $12-23$ & 1246 & $(28.8)$ & 2255 & $(24.0)$ & 1 & \\
\hline $24-35$ & 1066 & $(24.6)$ & 2347 & $(24.9)$ & $1.22(1.10$ to 1.34$)$ & 0.000 \\
\hline $36-47$ & 1011 & (23.3) & 2367 & $(25.1)$ & 1.30 (1.17 to 1.43$)$ & 0.000 \\
\hline $48-59$ & 1008 & (23.3) & 2445 & (26.0) & 1.34 (1.21 to 1.48$)$ & 0.000 \\
\hline \multicolumn{7}{|l|}{ Child's birth order } \\
\hline First & 1675 & $(38.7)$ & 3254 & $(34.6)$ & 1 & \\
\hline Second-fourth & 2413 & $(55.7)$ & 5120 & $(54.4)$ & 1.29 (1.21 to 1.37$)$ & 0.000 \\
\hline$\geq 5^{\text {th }}$ & 243 & $(5.6)$ & 1040 & $(11.0)$ & 1.41 (1.27 to 1.57$)$ & 0.000 \\
\hline \multicolumn{7}{|l|}{ Mother's age (years) } \\
\hline $15-19$ & 67 & $(1.5)$ & 195 & $(2.1)$ & 1 & \\
\hline $20-24$ & 704 & (16.2) & 1677 & $(17.8)$ & 0.82 (0.61 to 1.10$)$ & 0.178 \\
\hline $25-29$ & 1219 & (28.2) & 2709 & $(28.8)$ & 0.76 (0.57 to 1.02$)$ & 0.064 \\
\hline $30-34$ & 1166 & $(26.9)$ & 2288 & $(24.3)$ & 0.67 (0.51 to 0.90$)$ & 0.007 \\
\hline $35-39$ & 815 & (18.8) & 1595 & (16.9) & 0.67 (0.50 to 0.90$)$ & 0.007 \\
\hline $40-44$ & 301 & $(7.0)$ & 803 & $(8.5)$ & $0.92(0.67$ to 1.25$)$ & 0.579 \\
\hline $45-49$ & 59 & $(1.4)$ & 147 & (1.6) & 0.86 (0.57 to 1.29$)$ & 0.458 \\
\hline \multicolumn{7}{|l|}{ Mother's marital status } \\
\hline Married & 4159 & $(96.0)$ & 9009 & $(95.7)$ & 1 & \\
\hline Living with partner & 50 & $(1.2)$ & 126 & $(1.3)$ & $1.16(0.84$ to 1.62$)$ & 0.368 \\
\hline Widowed & 37 & $(0.9)$ & 81 & $(0.9)$ & 1.01 (0.68 to 1.49$)$ & 0.958 \\
\hline Divorced & 70 & $(1.6)$ & 161 & $(1.7)$ & $1.06(0.80$ to 1.41$)$ & 0.678 \\
\hline No longer living together & 11 & $(0.3)$ & 32 & $(0.3)$ & 1.34 (0.68 to 2.67$)$ & 0.400 \\
\hline Never in union & 4 & $(0.0)$ & 5 & $(0.1)$ & $0.58(0.15$ to 2.15$)$ & 0.413 \\
\hline \multicolumn{7}{|c|}{ Family size (number of household members) } \\
\hline$\leq 4$ & 1746 & $(40.3)$ & 3568 & $(37.9)$ & 1 & \\
\hline $5-9$ & 2381 & $(55.0)$ & 5256 & $(55.8)$ & 1.08 (1.00 to 1.16$)$ & 0.044 \\
\hline$\geq 10$ & 204 & $(4.7)$ & 590 & $(6.3)$ & $1.42(1.20$ to 1.68$)$ & 0.000 \\
\hline
\end{tabular}


Table 2 Continued

\begin{tabular}{|c|c|c|c|c|c|c|}
\hline \multirow{2}{*}{ Characteristics } & \multicolumn{4}{|c|}{ Status (\%) } & \multirow{2}{*}{$\begin{array}{l}\text { Unadjusted OR } \\
(95 \% \mathrm{Cl})\end{array}$} & \multirow[b]{2}{*}{ p Value } \\
\hline & \multicolumn{2}{|c|}{ Fully immunised } & \multicolumn{2}{|c|}{ Unimmunised } & & \\
\hline \multicolumn{7}{|l|}{ Mother's educational level } \\
\hline Higher & 756 & $(17.5)$ & 1063 & (11.3) & 1 & \\
\hline Secondary & 2451 & $(56.6)$ & 4770 & $(50.7)$ & 1.38 (1.25 to 1.54$)$ & 0.000 \\
\hline Primary & 1081 & $(25.0)$ & 3210 & (34.1) & 2.11 (1.88 to 2.37 ) & 0.000 \\
\hline No education & 43 & $(0.9)$ & 371 & (3.9) & 6.14 (4.41 to 8.53 ) & 0.000 \\
\hline \multicolumn{7}{|l|}{ Father's educational level } \\
\hline Higher & 717 & $(16.6)$ & 1023 & (10.9) & 1 & \\
\hline Secondary & 2508 & $(58.0)$ & 4930 & $(52.5)$ & 1.38 (1.24 to 1.53$)$ & 0.000 \\
\hline Primary & 1054 & $(24.4)$ & 3150 & (33.5) & 2.09 (1.86 to 2.36$)$ & 0.000 \\
\hline No education & 42 & $(1.0)$ & 269 & $(2.9)$ & 4.49 (3.20 to 6.30$)$ & 0.000 \\
\hline Don’t know & 3 & $(0.0)$ & 21 & $(0.2)$ & 4.91 (1.46 to 16.5$)$ & 0.010 \\
\hline \multicolumn{7}{|l|}{ Mother's occupation } \\
\hline Professional & 428 & (9.9) & 590 & (6.3) & 1 & \\
\hline Agricultural & 405 & $(9.4)$ & 1450 & $(15.4)$ & 2.60 (2.20 to 3.07$)$ & 0.000 \\
\hline Industrial & 480 & $(11.1)$ & 1091 & $(11.6)$ & 1.65 (1.40 to 1.94$)$ & 0.000 \\
\hline Clerical, services and sales & 1069 & $(24.7)$ & 2167 & $(23.0)$ & 1.47 (1.27 to 1.70$)$ & 0.000 \\
\hline Did not work & 1944 & $(44.9)$ & 4108 & $(43.7)$ & 1.53 (1.34 to 1.76$)$ & 0.000 \\
\hline \multicolumn{7}{|l|}{ Father's occupation } \\
\hline Professional & 520 & $(12.0)$ & 816 & $(8.7)$ & 1 & \\
\hline Agricultural & 809 & $(18.7)$ & 2741 & $(29.2)$ & 2.16 (1.89 to 2.47$)$ & 0.000 \\
\hline Industrial & 1584 & $(36.7)$ & 3300 & $(35.1)$ & 1.33 (1.17 to 1.50$)$ & 0.000 \\
\hline Clerical, services and sales & 1350 & $(31.2)$ & 2359 & $(25.1)$ & 1.11 (0.98 to 1.27$)$ & 0.102 \\
\hline Did not work & 58 & $(1.4)$ & 167 & $(1.8)$ & 1.83 (1.33 to 2.52$)$ & 0.000 \\
\hline Don’t know & 2 & $(0.0)$ & 10 & $(0.1)$ & 3.19 (0.70 to 14.6$)$ & 0.136 \\
\hline \multicolumn{7}{|c|}{ Mother's exposure to media (newspaper, magazine, radio or television) } \\
\hline At least once a week & 3814 & $(88.1)$ & 7714 & $(82.0)$ & 1 & \\
\hline Less than once a week & 373 & (8.6) & 1154 & $(12.2)$ & $1.53(1.35$ to 1.73$)$ & 0.000 \\
\hline Not at all & 142 & (3.3) & 544 & $(5.8)$ & 1.89 (1.57 to 2.29$)$ & 0.000 \\
\hline \multicolumn{7}{|l|}{ Mother's tobacco use history } \\
\hline Smokes nothing & 4246 & $(98.0)$ & 9071 & $(96.4)$ & 1 & \\
\hline Uses tobacco & 85 & $(2.0)$ & 339 & $(3.6)$ & 1.87 (1.47 to 2.37$)$ & 0.000 \\
\hline \multicolumn{7}{|l|}{ Enabling resources } \\
\hline \multicolumn{7}{|l|}{ Household wealth index } \\
\hline Richest & 914 & $(21.1)$ & 1194 & $(12.7)$ & 1 & \\
\hline Richer & 834 & $(19.2)$ & 1442 & $(15.3)$ & $1.32(1.17$ to 1.49$)$ & 0.000 \\
\hline Middle & 883 & $(20.4)$ & 1621 & $(17.2)$ & 1.41 (1.25 to 1.58$)$ & 0.000 \\
\hline Poorer & 848 & (19.6) & 1874 & $(19.9)$ & 1.69 (1.50 to 1.90$)$ & 0.000 \\
\hline Poorest & 852 & (19.7) & 3283 & (34.9) & 2.95 (2.63 to 3.31$)$ & 0.000 \\
\hline \multicolumn{7}{|l|}{ Covered by health insurance } \\
\hline Yes & 1993 & $(46.0)$ & 3587 & $(38.1)$ & 1 & \\
\hline No & 2336 & $(54.0)$ & 5820 & $(61.9)$ & 1.38 (1.29 to 1.49$)$ & 0.000 \\
\hline \multicolumn{7}{|l|}{ Antenatal care } \\
\hline Received some care & 3668 & $(99.0)$ & 7193 & $(94.8)$ & 1 & \\
\hline Received no care & 38 & $(1.0)$ & 394 & $(5.2)$ & 5.29 (3.78 to 7.39$)$ & 0.000 \\
\hline
\end{tabular}


Table 2 Continued

\begin{tabular}{|c|c|c|c|c|c|c|}
\hline \multirow[b]{2}{*}{ Characteristics } & \multicolumn{4}{|c|}{ Status (\%) } & \multirow{2}{*}{$\begin{array}{l}\text { Unadjusted OR } \\
(95 \% \mathrm{Cl})\end{array}$} & \multirow[b]{2}{*}{ p Valu } \\
\hline & \multicolumn{2}{|c|}{ Fully immunised } & \multicolumn{2}{|c|}{ Unimmunised } & & \\
\hline \multicolumn{7}{|l|}{ Postnatal care } \\
\hline Received some care & 2732 & $(73.8)$ & 4663 & $(61.7)$ & 1 & \\
\hline Received no care & 958 & $(25.9)$ & 2855 & $(37.8)$ & 1.75 (1.60 to 1.90$)$ & 0.000 \\
\hline Don’t know & 14 & $(0.3)$ & 39 & $(0.5)$ & 1.63 (0.88 to 3.01$)$ & 0.117 \\
\hline \multicolumn{7}{|l|}{ Child's place of delivery } \\
\hline Home & 1376 & $(31.8)$ & 4949 & $(52.8)$ & 1 & \\
\hline Public health institution & 1041 & $(24.1)$ & 1486 & (15.9) & 0.40 (0.36 to 0.44$)$ & 0.000 \\
\hline Private health institution & 1905 & $(44.0)$ & 2918 & (31.1) & $0.43(0.40$ to 0.46$)$ & 0.000 \\
\hline Other & 6 & $(0.1)$ & 22 & $(0.2)$ & 1.02 (0.41 to 2.52$)$ & 0.967 \\
\hline \multicolumn{7}{|l|}{ Distance to health facilities } \\
\hline Not a big problem & 3885 & $(89.9)$ & 8030 & $(85.6)$ & 1 & \\
\hline Big problem & 438 & (10.1) & 1354 & $(14.4)$ & 1.50 (1.33 to 1.68$)$ & 0.000 \\
\hline \multicolumn{7}{|c|}{ Maternal healthcare decision-making } \\
\hline By mother herself & 1461 & $(34.7)$ & 3297 & $(36.1)$ & 1 & \\
\hline Jointly with husband & 2193 & $(52.1)$ & 4374 & $(47.9)$ & 0.88 (0.82 to 0.96$)$ & 0.003 \\
\hline Husband alone & 543 & (12.9) & 1429 & $(15.7)$ & $1.17(1.04$ to 1.31$)$ & 0.010 \\
\hline By others & 10 & $(0.3)$ & 24 & $(0.3)$ & 1.06 (0.51 to 2.23$)$ & 0.870 \\
\hline \multicolumn{7}{|c|}{ Child healthcare decision-making } \\
\hline By mother herself & 1469 & $(37.0)$ & 3028 & $(36.0)$ & 1 & \\
\hline Jointly with husband & 2015 & $(50.8)$ & 4240 & $(50.4)$ & $1.12(0.99$ to 1.28$)$ & 0.076 \\
\hline Husband alone & 424 & $(10.7)$ & 983 & $(11.7)$ & $1.02(0.94$ to 1.11$)$ & 0.621 \\
\hline By others & 59 & $(1.5)$ & 166 & $(1.9)$ & $1.36(1.01$ to 1.85$)$ & 0.045 \\
\hline
\end{tabular}

children ranged from 1.22 to 1.34 . Similarly, children who were not first born had significantly higher chance of being unimmunised. The odds of being unimmunised increased as the child's age and birth order increased $(\mathrm{p}<0.000)$.

We found that children whose mothers were 30-39 years old at the time of the survey were less likely to be unimmunised (OR 0.67; 95\% CI 0.50 to 0.90 ). However, there was no clear trend across the age groups. We also found that children who came from bigger families were significantly more likely to be unimmunised. The likelihood increased by $8 \%$ up to $42 \%$. As the number of household members increased, the likelihood of a child to be unimmunised increased $(\mathrm{p}<0.000)$.

Although their marital status was not a significant predictor of coverage, each parent educational attainment was significantly associated with coverage. As parents' educational attainment increased, the likelihood of being unimmunised decreased $(p<0.000)$. Hence, children from uneducated parents had the highest odds of being unimmunised. Those whose mothers had no education were at least six times more likely to be unimmunised (OR 6.14; CI $95 \% 4.41$ to 8.53 ). Likewise, children whose fathers were uneducated had greater than fourfold chance of being unimmunised (OR 4.49; 95\% CI 3.20 to 6.30 ).
Additionally, parents' occupation, mother's exposure to media and mother's tobacco use history were significantly associated with coverage. Across the occupational groups, children whose parents worked in agriculture had the highest odds of being unimmunised. Children whose mothers worked in agriculture were 2.6 times more likely to be unimmunised (OR 2.60; 95\% CI 2.20 to 3.07), while children whose fathers worked in agriculture were 2.16 times more likely to be unimmunised (OR 2.16; $95 \%$ CI 1.89 to 2.47). Regarding mother's exposure to media, the child's likelihood of being unimmunised increased as the frequency of media exposure decreased $(p<0.000)$. Finally, children whose mothers smoked tobacco around the time of the survey had $87 \%$ higher chance of being unimmunised (OR 1.87; 95\% CI 1.47 to 2.37).

We found that as the household wealth index increased, the likelihood of being unimmunised decreased $(p<0.000)$. Hence, children from poorest households had the highest odds of being unimmunised (OR 2.95; $95 \%$ CI 2.63 to 3.31). We also found that children who had no health insurance were significantly more likely to be unimmunised compared with those who had insurance (OR 1.38; 95\% CI 1.29 to 1.49).

Our univariate analysis indicated that antenatal and postnatal care visits were significant predictors of 
coverage in Indonesia. Our results showed that children who were born without antenatal care were at least five times more likely to be unimmunised (OR 5.29; $95 \%$ CI 3.78 to 7.39 ). Likewise, those who were born without postnatal care were $75 \%$ more likely to be unimmunised (OR $1.75 ; 95 \%$ CI 1.60 to 1.90 ).

In terms of access to health services, we found that children who were born in health institution were significantly less likely to be unimmunised compared with those who were born at home. Specifically, children who were born at public health institution had the least likelihood of being unimmunised (OR 0.40; 95\% CI 0.36 to 0.44 ). In addition, children whose mothers think that distance to health facilities was a big problem had $50 \%$ higher chance of being unimmunised (OR 1.50; $95 \%$ CI 1.33 to $1.68)$.

\section{Multivariate analysis}

Out of the 22 independent variables, child's sex and mother's marital status were excluded. table 3 summarised the significant results of our multilevel logistic regression analysis between the remaining 20 independent variables and the likelihood of being unimmunised.

After accounting for the other remaining variables, geographic region and place of residence were significantly associated with coverage. The likelihood of being unimmunised was highest among children who lived in Maluku and Papua. Children who lived in this region were almost twice as likely to be unimmunised compared with those who lived in Java (AOR 1.94; 95\% CI 1.42 to 2.64). Similarly, children who lived in Sumatera had considerably higher odds of being unimmunised (AOR $1.51 ; 95 \%$ CI 1.24 to 1.83$)$. In contrast, children from Bali and Nusa Tenggara were less likely to be unimmunised (AOR 0.71; 95\% CI 0.54 to 0.94). Those who lived in rural areas were also less likely to be unimmunised compared with their urban counterparts (AOR 0.82; $95 \%$ CI 0.69 to 0.96).

The likelihood of being unimmunised differed significantly across the age groups. Older children were more likely to be unimmunised compared with those in the youngest age group. The odds ranged from 1.24 (95\% CI 1.08 to 1.42 ) to 1.39 (95\% CI 1.20 to 1.60 ). Of all age groups, children aged 36-47 months had the highest odds of being unimmunised (AOR 1.39; 95\% CI 1.20 to $1.60)$.

The child's birth order and family size were also significantly correlated with immunisation status. As a child's birth order or family size increased, the likelihood of being unimmunised also increased. A second child was $18 \%$ more likely to be unimmunised compared with a first child (AOR 1.18; 95\% CI 1.03 to 1.35), while a fifth child had $68 \%$ higher chance of being unimmunised (AOR 1.68; 95\% CI 1.28 to 2.19). Accordingly, children who came from bigger families had higher likelihood of being unimmunised. Those who lived in households with 10 or more family members were $47 \%$ more likely to be unimmunised (AOR 1.47; 95\% CI 1.11 to 1.93 ).
Table 3 Multivariate analysis results for factors significantly associated with low immunisation coverage of children aged 12-59 months in Indonesia

\begin{tabular}{|c|c|c|}
\hline Characteristics & Adjusted OR (95\% Cl) & p Value \\
\hline \multicolumn{3}{|l|}{ External environment } \\
\hline \multicolumn{3}{|l|}{ Geographic region } \\
\hline Sumatera & 1.51 (1.24 to 1.83$)$ & 0.000 \\
\hline Java & 1 & \\
\hline Bali and Nusa Tenggara & 0.71 (0.54 to 0.94$)$ & 0.016 \\
\hline Maluku and Papua & 1.94 (1.42 to 2.64$)$ & 0.000 \\
\hline \multicolumn{3}{|l|}{ Place of residence } \\
\hline Urban & 1 & \\
\hline Rural & $0.82(0.69$ to 0.96$)$ & 0.013 \\
\hline \multicolumn{3}{|c|}{ Predisposing characteristics } \\
\hline \multicolumn{3}{|l|}{ Child's age (months) } \\
\hline $12-23$ & 1 & \\
\hline $24-35$ & 1.24 (1.08 to 1.42$)$ & 0.002 \\
\hline $36-47$ & 1.39 (1.20 to 1.60$)$ & 0.000 \\
\hline $48-59$ & 1.36 (1.17 to 1.58$)$ & 0.000 \\
\hline \multicolumn{3}{|l|}{ Child's birth order } \\
\hline $1 \mathrm{st}$ & 1 & \\
\hline 2nd-4th & 1.18 (1.03 to 1.35$)$ & 0.016 \\
\hline$\geq 5$ th & 1.68 (1.28 to 2.19$)$ & 0.000 \\
\hline
\end{tabular}

Family size
(number of household members)

\begin{tabular}{|c|c|}
\hline$\leq 4$ & 1 \\
\hline$\geq 10$ & 1.47 (1.11 to 1.93 ) \\
\hline
\end{tabular}

$\begin{array}{lll}\text { Mother's educational level } & & \\ \text { Higher } & 1 & \\ \begin{array}{l}\text { No education } \\ \text { Father's occupation }\end{array} & 2.13(1.22 \text { to } 3.72) & 0.008 \\ \quad \begin{array}{l}\text { Professional } \\ \text { Clerical, services and } \\ \text { sales }\end{array} & 0.82(0.67 \text { to } 1.00) & 0.047\end{array}$

\begin{tabular}{|c|c|c|}
\hline \multicolumn{3}{|l|}{ Enabling resources } \\
\hline \multicolumn{3}{|l|}{ Household wealth index } \\
\hline Richest & 1 & \\
\hline Poorer & 1.30 (1.06 to 1.59$)$ & 0.011 \\
\hline Poorest & 1.58 (1.26 to 1.99$)$ & 0.000 \\
\hline \multicolumn{3}{|c|}{ Covered by health insurance } \\
\hline Yes & 1 & \\
\hline No & 1.16 (1.04 to 1.30$)$ & 0.010 \\
\hline \multicolumn{3}{|l|}{ Antenatal care } \\
\hline Received some care & 1 & \\
\hline Received no care & 3.28 (2.09 to 5.15$)$ & 0.000 \\
\hline \multicolumn{3}{|l|}{ Postnatal care } \\
\hline Received some care & 1 & \\
\hline Received no care & 1.50 (1.34 to 1.69$)$ & 0.000 \\
\hline
\end{tabular}

Continued 


\begin{tabular}{|c|c|c|}
\hline Characteristics & Adjusted OR (95\% Cl) & p Value \\
\hline \multicolumn{3}{|l|}{ Child's place of delivery } \\
\hline Home & 1 & \\
\hline Public health institution & $0.55(0.47$ to 0.64$)$ & 0.000 \\
\hline Private health institution & $0.62(0.54$ to 0.72$)$ & 0.000 \\
\hline \multicolumn{3}{|c|}{ Maternal healthcare decision-making } \\
\hline By herself & 1 & \\
\hline Jointly with husband & $0.86(0.76$ to 0.96$)$ & 0.010 \\
\hline
\end{tabular}

Children whose mothers had no education were at least twice as likely to be unimmunised than those whose mothers were high school graduates or higher (AOR 2.13; $95 \%$ CI 1.22 to 3.72). Similarly, the odds of being unimmunised were significantly higher among the poorer (AOR 1.30; 95\% CI 1.06 to 1.59) and the poorest (AOR $1.58 ; 95 \%$ CI 1.26 to 1.99$)$. Also, those without health insurance were more likely to be unimmunised (AOR 1.16 ; $95 \%$ CI 1.04 to 1.30 ).

The odds of being unimmunised were strikingly higher among children without antenatal or postnatal care. Children who were born without antenatal care were more than three times as likely to be unimmunised (AOR 3.28; $95 \%$ CI 2.09 to 5.15). Likewise, those who had no postnatal care had a $50 \%$ higher chance of being unimmunised (AOR 1.50; 95\% CI 1.34 to 1.69). Additionally, children who were born in health institution were less likely to be unimmunised compared with those who were born at home (AOR 0.55; 95\% CI 0.47 to 0.64 ). Furthermore, children whose parents jointly decided on maternal healthcare and whose fathers worked in clerical, services and sales were significantly less likely to be unimmunised (AOR 0.86; 95\% CI 0.76 to 0.96 and AOR 0.82; 95\% CI 0.67 to 1.00 , respectively).

\section{DISCUSSION}

\section{Main findings}

Our study investigated, for the first time, the factors associated with routine immunisation coverage of children aged 12-59 months in Indonesia, using data from 2012 IDHS. Our analysis revealed that only $31.5 \%$ of the children had been fully immunised. After accounting for all confounders, 13 factors were significantly associated with low coverage in Indonesia: geographic region, place of residence, child's age, child's birth order, family size, mother's education, father's occupation, household wealth index, insurance coverage, antenatal care, postnatal care, child's place of delivery and maternal healthcare decision-making.

There are discrepancies between the coverage level reported by the officials and the one discovered in this study. In 2012, the Indonesian MOH reported coverage level of $86.8 \%$. $^{31}$ The coverage level determined through
2012 IDHS is therefore much lower than that contained in the official report.

While our study analysed cross-sectional survey data, the official report used administrative data which are commonly employed to assess immunisation coverage in low-resource settings. ${ }^{32}$ The estimate is obtained by dividing the number of doses administered at health services by the expected target population. ${ }^{32}{ }^{33}$ Although this is readily available, results can be unreliable, particularly when there are uncertainties surrounding the total number of age-eligible children. ${ }^{32} 34$

The discrepancy between estimates obtained from administrative and survey data have also been reported in the past. ${ }^{34-37}$ Administrative estimates tend to be higher than those obtained from the survey, ${ }^{33}$ which is observed in our finding as well. Comparisons of administrative and survey estimates are made more complicated by the fact that the number of age-eligible children included in each analysis differs. ${ }^{33}$ The estimate from administrative data includes children aged $0-11$ months, while the survey usually includes children aged up to 59 months. ${ }^{33} 34$ The coverage from $\mathrm{MOH}$ report was of children aged 0-11 months, because they are the youngest group eligible to receive the full schedule of routine immunisation. Measles vaccine, for example, is the last one on the schedule and is given starting at the age of 9 months. However, it could be administered up to the age of 12 months. ${ }^{38}$ There are also booster campaign and backlog fighting initiative for children up to 3 years of age, as well as other supplemental immunisation activities which targeted children aged 9-59 months. This is all part of routine immunisation programme in Indonesia. ${ }^{38}$ Therefore, estimates from administrative data would not have covered the entire target population of routine immunisation coverage. This indicates a weakness in the surveillance system and highlights the need of quality assurance of immunisation data.

\section{Factors associated with immunisation coverage}

After accounting for all observed confounders, geographic region was significantly associated with coverage. The six geographic regions used in our analysis represented the six largest islands in Indonesia. Each has its own population density, religious affiliation and political situation, economic potential and level of development. Our analysis suggested that children from the Maluku and Papua region had the highest odds of being unimmunised. The Maluku and Papua region is located in the easternmost part of Indonesia and is economically deprived. It is the largest yet least developed region with ongoing conflicts. Eligible children most likely lived in remote areas without access to health services. It is therefore not surprising that we found these children to have the highest likelihood of being unimmunised. Our research confirms that geographical disparities may contribute to low coverage, particularly in developing countries with a large population. ${ }^{12}$ Similar findings were reported from India ${ }^{38}$ and Nigeria. ${ }^{14}$ 
Children from urban areas have been reported to have better immunisation status compared with their rural counterparts. ${ }^{30}$ By contrast, our results revealed that children who lived in rural areas were less likely to be unimmunised. Although health services are better and more easily accessible in urban areas compared with rural areas, ${ }^{28}$ this fact likely masks the extent of urban poverty. ${ }^{30}$ Estimates suggest that one-third of urban populations in developing countries are actually living in slums. ${ }^{39}$ With limited access to health services and poor quality of life, it is certainly likely that urban children had higher odds of being unimmunised. Unfortunately, we lacked information to distinguish between urban areas with higher socioeconomic status and the slums. Further research in this field could assist strategic planning and resource allocation.

Our analysis revealed that children of older age groups were significantly more likely to be unimmunised compared with those in the youngest group. In other words, later birth years were associated with better coverage. It may indicate a positive trend of the immunisation programme performance over the years. ${ }^{40}$ In the 5 years preceding the survey, the Indonesian government showed strong commitment towards immunisation programme. In line with global and national commitment to reduce the number of preventable child deaths, there were sharp increase in central government's budget for immunisation programme. Between the year of 2007 and 2008 alone, it increased by $40 \% .{ }^{41}$ In 2010 , immunisation programme became a national priority under Presidential Instructions No 1 and No $3 .^{41}$ Among the key performance indicators was acceleration of coverage, which gradually increased between the year 2007 and 2012. ${ }^{11}$ Our finding suggested that immunisation policy development in Indonesia might have played a role in improving coverage.

As the birth order increases, the likelihood of a child being unimmunised increases. A possible explanation is that parents may have developed confidence in their child's healthcare as a result of years of experience from previous children and could dismiss the importance of immunisation. ${ }^{43}$ On the contrary, it could be that the first-born experienced adverse reaction to immunisation, leading the parents to believe that immunisation was risky. ${ }^{43}$

Consistently, children who came from larger families were more likely to be unimmunised. The number of household members has been linked with health outcome in many developing countries. As the number of family members increases, the quality of care they receive decreases. ${ }^{28} 42$ This is because limited family resources are spread more sparsely, reducing the level of health investment received by each household member.

Our data revealed that children whose mothers had no education were at least twice as likely to be unimmunised compared with those whose mothers were high school graduates. This indicates that maternal education is a major determinant of immunisation coverage in
Indonesia. The obvious explanation is that literacy and educational attainment facilitate understanding of the recommended immunisation schedule. ${ }^{40}$ This suggests that improving the programme to achieve the target of herd immunity might be helpful only in the short term. It highlights the need for a long-term investment in human capital, especially in Indonesian women. ${ }^{28}$

Children whose fathers work in clerical, services or sales were less likely to be unimmunised compared with children of professionals. This is unexpected, given that people who work in clerical, services or sales are usually of a lower socioeconomic status and may find it difficult to obtain permission for work leave to enable their children to be immunised. ${ }^{14}$ Nonetheless, our result confirmed previous finding which reported similar association in Bangladesh. ${ }^{16}$ Fathers who were professionals were significantly less likely to have their children fully immunised, as they tend to work long hours and are too preoccupied to be involved in their child's healthcare.

Wealth is a well-established indicator of access to health services in many countries regardless of income groups. Our analysis indicated that children from poorer and poorest households were more likely to be unimmunised. Given that immunisation services are available free of charge in Indonesia, the indirect cost of immunisation may be the relevant factor instead. Lost work days and transport costs could deter parents from enabling their child to be immunised. ${ }^{44} 45$ The likelihood of being unimmunised was also higher among children without health insurance. This is reasonable because health insurance alleviate the burden of out-of-pocket spending, including indirect cost of immunisation. Most studies from developing countries have reported that health insurance has a positive impact on increasing healthcare use. ${ }^{46}$

The odds of being unimmunised were considerably higher among children without antenatal and postnatal care. Children who were born without antenatal care were at least three times more likely to be unimmunised. Likewise, children who did not receive postnatal care had a $50 \%$ greater chance of being unimmunised (AOR 1.50; $95 \%$ CI 1.34 to 1.69$)$. This finding reflects the importance of information received by mothers during antenatal and postnatal care. Their visits might have equipped them with the necessary knowledge on child immunisation. In Indonesia, at least four antenatal visits are recommended during pregnancy. However, this service has been underused ${ }^{29}$ and the negative implication of missed opportunities for immunisation coverage is almost certain.

There was a significant association between a child's place of delivery and immunisation coverage. Children who were born in public or private health institution were less likely to be unimmunised compared with those who were born at home. This is most likely because children who were born at health facilities were vaccinated, or were given recommendation to be vaccinated, immediately after birth. Furthermore, a study from Kenya has shown that women who deliver at home or unassisted may have 
a distrust of modern medicine and a stronger preference for traditional remedies. ${ }^{47}$ By extension, they could have a sceptical view about childhood immunisation. ${ }^{48}$

Our analysis also showed that children who were born in private health institution had greater odds of being unimmunised relative to those who were born in public health institution (AOR 0.62; 95\% CI 0.54 to 0.72 and AOR $0.55 ; 95 \%$ CI 0.47 to 0.64 , respectively). In Indonesia, private health institution do not benefit from government's healthcare funding, although they do operate under the ministerial decree to deliver routine immunisation. Consequently, there is no financial incentive for private health institution to ensure that children are fully immunised. Therefore, strengthening the implementation of the ministerial decree for private health institution may help in improving immunisation coverage.

Children whose parents jointly decide on maternal healthcare were less likely to be unimmunised. This emphasises the importance of family support in using health services, confirming what had been outlined by Andersen in his theoretical framework. ${ }^{13}$ The combination of both mother's autonomy and father's involvement in the decision-making process seemed to be essential. This suggests that interventions which educate and involve fathers might have the potential to increase immunisation coverage. ${ }^{49}$

Although our findings were consistent with reports from other lower middle income countries, we found that several factors were not significant predictors of coverage in Indonesia. Despite reports from India, a child's sex did not affect coverage in Indonesia. This is consistent with studies from Nigeria undertaken by $\mathrm{Antai}^{14}$ and Adebiyi. ${ }^{50}$ It appears that gender could predict immunisation status only if the child is from a society where gender inequality is prevalent. ${ }^{50}$ We also found no correlation between a mother's age and her child's immunisation status. Previous studies have reported that the odds of a child being unimmunised is greater for both younger and older mothers, suggesting a U-shaped association. ${ }^{28}$ However, this association might be mitigated by patterns of other coexisting variables in our analysis, such as the child's birth order and the mother's level of education.

\section{Strengths and limitations}

To our knowledge, this study was the first to identify factors associated with routine immunisation coverage of children in Indonesia. We used the 2012 IDHS dataset, which was the most recent one. The large sample size allowed us to analyse many potential predictors simultaneously. It also increased the validity of our results. Furthermore, we used multilevel modelling to account for the hierarchical structure of the data. We have also adjusted our analysis to meet the local context and produce reliable estimates. However, our results should be considered in the light of potential limitations.

As with other secondary analysis of cross-sectional survey data, caution should be exercised in inferring causality between the socioeconomic factors and immunisation coverage. In addition, the nature of our data source and analysis potentially limit generalisability. There is a need to verify the validity of the observed associations using longitudinal data.

Information on a child's immunisation status was subject to bias, because we included mother's report as a source of information. As such, we relied on the mother's ability to recall her child's immunisation status accurately. Nonetheless, mother's report is considered a valid measure of coverage in the absence of a health card, especially in developing countries. ${ }^{51}$ We therefore believe that our reliance on mother's report is reasonable and not likely to have introduced bias into our study.

The selection of variables included in this study relied on the information available from the dataset. Other potential predictors that were previously identified in lower middle-income setting, such as ethnicity and religion, could not be assessed in this study. Categorisation of original responses from the survey might have also influenced the results.

The 2012 IDHS selected participants through a two-stage stratified sampling design. The primary sampling unit was the CBs and the complete list of households in each CB became the basis for second-stage sampling. However, there was no household identifier in the dataset as it may compromise the participants' anonymity. Therefore, we could only build a two-level model (ie, children nested within CBs) instead of a three-level model (ie, children within households nested within CBs). We recognise that children living in the same household could have shared similar health characteristics, which reflects parent-specific knowledge or beliefs on immunisation. ${ }^{12}$ However, our analysis of variables that served as a proxy of parent-specific knowledge or beliefs (ie, mother's exposure to media and mother's tobacco use history) emerged as being insignificant. Therefore, we have good reason to believe that this limitation is unlikely to have any impact on the validity of our analysis.

Finally, we classified immunisation status into 'fully immunised' and 'unimmunised' based on whether the child received full schedule of immunisation or otherwise. While other studies have used three distinct categories: fully immunised, partly immunised and completely unimmunised, we dichotomised our outcome variable and did not distinguish partly immunised from completely unimmunised. This is because our study focused on factors associated with the coverage of routine immunisation, which is the complete uptake of recommended vaccination represented by the fully immunised. Reasons for Indonesian children being partly immunised and completely unimmunised might differ, and future research can potentially address this question.

\section{CONCLUSION}

In this study, we examined variables that contribute to a child's immunisation status in Indonesia. Our results suggested that immunisation coverage is suboptimal 
due to socioeconomic factors. Among the demographic groups, children who lived in Maluku and Papua region and children from the poorest households have the lowest coverage. We also identified maternal education and antenatal care visits as key factors that policy-makers can target to improve immunisation coverage in Indonesia.

Beyond mapping trend of coverage nationally, we recommend regular monitoring and evaluation of coverage at province and district levels. This is important to identify high-risk areas and implement targeted activities in the communities. Increasing awareness and financial support for deprived households with more than one child may help reduce the indirect cost and motivate parents to immunise their children. Promoting equal access to education, encouraging institutional deliveries and scaling up use of antenatal and postnatal care may significantly improve coverage in Indonesia.

Acknowledgements We are grateful to the ICF International for granting us access to the datasets and to the Indonesia Endowment Fund for Education (Lembaga Pengelola Dana Pendidikan) for funding PH a master scholarship at the Department of Primary Care and Public Health Sciences, King's College London. This analysis was part of PH dissertation.

Contributors PH and AD participated in the design of the study. PH performed the analysis and prepared the manuscript. $A D$ provided data analysis advice and revision of the manuscript. All authors read and approved the final manuscript.

Funding This study was funded by Indonesia Endowment Fund for Education.

Competing interests PH had financial support from LPDP for the submitted work, no financial relationships with any organisations that might have an interest in the submitted work in the previous three years; no other relationships or activities that could appear to have influenced the submitted work.

Ethics approval This study did not require ethical approval as it used unidentifiable secondary data. Permission to use the dataset was obtained from ICF International, who obtained approval to conduct IDHS in 2012. No identifiable information was included in the dataset and no attempt was made to identify any individual interviewed in the survey.

Provenance and peer review Not commissioned; externally peer reviewed.

Data sharing statement The electronic datasets analysed in this study are available for legitimate research purposes from the Measure DHS website.

Open Access This is an Open Access article distributed in accordance with the Creative Commons Attribution Non Commercial (CC BY-NC 4.0) license, which permits others to distribute, remix, adapt, build upon this work non-commercially, and license their derivative works on different terms, provided the original work is properly cited and the use is non-commercial. See: http://creativecommons.org/ licenses/by-nc/4.0/

(c) Article author(s) (or their employer(s) unless otherwise stated in the text of the article) 2017. All rights reserved. No commercial use is permitted unless otherwise expressly granted.

\section{REFERENCES}

1. World Health Organisation. The expanded programme on immunization. 2013 http://www.who.int/immunization/programmes_ systems/supply_chain/benefits_of_immunization/en/ (accessed 17 Jun 2016).

2. Duclos P, Okwo-Bele JM, Gacic-Dobo M, et al. Global immunization: status, progress, challenges and future. BMC Int Health Hum Rights 2009;9:1.

3. World Health Organisation. Global Vaccine Action Plan. Geneva: WHO Press, 2013

4. World Health Organisation. Immunization coverage. 2016 http://www. who.int/mediacentre/factsheets/fs378/en/ (accessed 17 Jun 2016).

5. United Nations. Sustainable development goals. 2015 http://www.u n.org/sustainabledevelopment/health/ (accessed 17 Jun 2016).
6. World Health Organisation. Global immunisation data. $2015 \mathrm{http}: / /$ www.who.int/immunization/monitoring_surveillance/Global Immunization_Data.pdf?ua=1 (accessed 17 Jun 2016).

7. World Bank. Indonesia. 2016. http://data.worldbank.org/country/ indonesia (accessed 17 Jun 2016).

8. Statistics Indonesia. Result of Population Census 2010. Jakarta: Badan Pusat Statistik, 2012

9. United Nations. World Population Prospects: The 2015 Revision, Key Findings and Advance Tables. Newyork: United Nations. 2015; Working Paper No. ESA/P/WP.241.

10. World Health Organisation. Indonesia: WHO Statistical Profile. 2015. http://www.who.int/gho/countries/idn.pdf?ua=1 (accessed 17 Jun 2016).

11. Ministry of Health. Basic Health Research. Jakarta: Kementerian Kesehatan Republik Indonesia, 2013.

12. Clouston $\mathrm{S}$, Kidman $\mathrm{R}$, Palermo T. Social inequalities in vaccination uptake among children aged 0-59 months living in Madagascar: an analysis of Demographic and Health Survey data from 2008 to 2009. Vaccine 2014;32:3533-9.

13. Andersen RM. Revisiting the behavioral model and access to medical care: does it matter? J Health Soc Behav 1995;36:1-10.

14. Antai D. Inequitable childhood immunization uptake in Nigeria: a multilevel analysis of individual and contextual determinants. BMC Infect Dis 2009;9:1.

15. Barata RB, Ribeiro MC, de Moraes JC, et al. Socioeconomic inequalities and vaccination coverage: results of an immunisation coverage survey in 27 Brazilian capitals, 2007-2008. J Epidemiol Community Health 2012;66:934-41.

16. Biswas SC, Darda MA, Alam MF. Factors affecting childhood immunisation in Bangladesh. Pak Dev Rev 2001;40:57-70.

17. Bondy JN, Thind A, Koval JJ, et al. Identifying the determinants of childhood immunization in the Philippines. Vaccine 2009;27:169-75.

18. Bugvi AS, Rahat R, Zakar R, et al. Factors associated with nonutilization of child immunization in Pakistan: evidence from the Demographic and Health Survey 2006-07. BMC Public Health 2014;14:1.

19. Gram L, Soremekun S, ten Asbroek A, et al. Socio-economic determinants and inequities in coverage and timeliness of early childhood immunisation in rural Ghana. Trop Med Int Health 2014;19:802-11.

20. Hungerford D, Macpherson P, Farmer S, et al. Effect of socioeconomic deprivation on uptake of measles, mumps and rubella vaccination in Liverpool, UK over 16 years: a longitudinal ecological study. Epidemiol Infect 2016;144:1201-11.

21. Ibnouf AH, Van den Borne HW, Maarse JAM. Factors influencing immunisation coverage among children under five years of age in Khartoum State, Sudan. S Afr Fam Pract 2007;49:14-14f.

22. Moore D, Castillo E, Richardson C, et al. Determinants of health status and the influence of primary health care services in Latin America, 1990-98. Int J Health Plann Manage 2003;18:279-92.

23. Rammohan A, Awofeso N. District-level variations in childhood immunizations in India: The role of socio-economic factors and health infrastructure. Soc Sci Med 2015;145:163-72.

24. Wiysonge CS, Uthman OA, Ndumbe PM, et al. Individual and contextual factors associated with low childhood immunisation coverage in sub-Saharan Africa: a multilevel analysis. PLoS One 2012; $7: \mathrm{e} 37905$

25. Statistics Indonesia. Badan Pusat Statistik-BPS), National Population and Family Planning Board (BKKBN), Kementerian Kesehatan (Kemenkes - MOH), and ICF International. 2013: indonesia demographic and health survey. Jakarta, Indonesia: BPS, BKKBN, Kemenkes, and ICF International, 2012.

26. Murray CJ, Shengelia B, Gupta N, et al. Validity of reported vaccination coverage in 45 countries. Lancet 2003;362:1022-7.

27. Burton A, Monasch R, Lautenbach B, et al. WHO and UNICEF estimates of national infant immunization coverage: methods and processes. Bull World Health Organ 2009;87:535-41.

28. Fernandez R, Rammohan A, Awofeso N. Correlates of first dose of measles vaccination delivery and uptake in Indonesia. Asian Pac $J$ Trop Med 2011;4:140-5.

29. Titaley CR, Dibley MJ, Roberts CL. Factors associated with underutilization of antenatal care services in Indonesia: results of Indonesia Demographic and Health Survey 2002/2003 and 2007. BMC Public Health 2010;10:485.

30. Shrivastwa N, Gillespie BW, Kolenic GE, et al. Predictors of vaccination in india for children aged 12-36 months. Am J Prev Med 2015;49:S435-44.

31. Ministry of Health. Indonesia Health Profile 2012. Jakarta: Kementerian Kesehatan Republik Indonesia, 2013. 
32. Luman ET, Worku A, Berhane Y, et al. Comparison of two survey methodologies to assess vaccination coverage. Int J Epidemiol 2007;36:633-41.

33. Zuber PL, Yaméogo KR, Yaméogo A, et al. Use of administrative data to estimate mass vaccination campaign coverage, Burkina Faso, 1999. J Infect Dis 2003;187(Suppl 1):S86-90.

34. Borgdoff MW, Walker GIA. Estimating vaccination coverage: routine information or sample survey? J Trop Med Hygiene 1988;91:35-42.

35. Vashishtha VM. Status of immunization and need for intensification of routine immunization in India. Indian Pediatr 2012;49:357-61.

36. Mathew JL. Inequity in childhood immunization in India: a systematic review. Indian Pediatr 2012;49:203-23.

37. Guyer B, Atangana S. A programme of multiple-antigen childhood immunization in Yaoundé, Cameroon: first-year evaluation, 19751976. Bull World Health Organ 1977;55:633.

38. Ministry of Health. Ministerial Decree No 1611/MENKES/SK/XI/2005 on the Implementation of Immunization. Jakarta: Kementerian Kesehatan Republik Indonesia, 2005.

39. World Bank. Urban Poverty and Slum Upgrading. 2016. http://go. worldbank.org/D7G2Q70170 (accessed 3 Aug 2016).

40. Schoeps A, Ouédraogo N, Kagoné M, et al. Socio-demographic determinants of timely adherence to BCG, Penta3, measles, and complete vaccination schedule in Burkina Faso. Vaccine 2013;32:96-102.

41. Ministry of Health. Comprehensive Multi Year Plan National Immunization Program Indonesia 2010-2014. Jakarta: Kementerian Kesehatan Republik Indonesia, 2010.
42. Abadura SA, Lerebo WT, Kulkarni U, et al. Individual and community level determinants of childhood full immunization in Ethiopia: a multilevel analysis. BMC Public Health 2015;15:1.

43. Gatchell M, Thind A, Hagigi F. Informing state-level health policy in India: the case of childhood immunizations in Maharashtra and Bihar. Acta Paediatr 2008;97:124-6.

44. Lanaspa M, Balcells $\mathrm{R}$, Sacoor $\mathrm{C}$, et al. The performance of the expanded programme on immunization in a rural area of Mozambique. Acta Trop 2015;149:262-6.

45. Mitchell S, Andersson N, Ansari NM, et al. Equity and vaccine uptake: a cross-sectional study of measles vaccination in Lasbela District, Pakistan. BMC Int Health Hum Rights 2009;9(Suppl 1):S7.

46. Aji B, De Allegri $M$, Souares $A$, et al. The impact of health insurance programs on out-of-pocket expenditures in Indonesia: an increase or a decrease? Int J Environ Res Public Health 2013;10:2995-3013.

47. Mason L, Dellicour S, Ter Kuile F, et al. Barriers and facilitators to antenatal and delivery care in western Kenya: a qualitative study. BMC Pregnancy Childbirth 2015;15:1.

48. Ushie BA, Fayehun OA, Ugal DB. Trends and patterns of under-5 vaccination in Nigeria, 1990-2008: what manner of progress? Child Care Health Dev 2014;40:267-74.

49. Brugha RF, Kevany JP, Swan AV. An investigation of the role of fathers in immunization uptake. Int J Epidemiol 1996;25:840-5.

50. Adebiyi F. Determinants of full child immunization among $12-23$ months old in Nigeria, MA thesis. University of Witwatersrand, 2013.

51. Langsten R, Hill K. The accuracy of mothers' reports of child vaccination: evidence from rural Egypt. Soc Sci Med 1998;46:1205-12. 